\title{
URETHRAL FOREIGN BODY MANAGEMENT: A CASE REPORT
}

\author{
MD NAZRUL ISLAM ${ }^{1}$, MA KASHEM ${ }^{2}$
}

${ }^{1}$ Department of Urology, SBMCH, Barisal , ${ }^{2}$ Department of Urology, SSMC, Dhaka

Bangladesh J. Urol. 2016; 19(2): 103-104

\section{Introduction :}

Some Homosexuals insert objects into their penis for pleasure. These includes pencils, pens, swizzle sticks, buckshut and glass beads[1]. Goldstone described the case of a man who inserted a piano wire in his penis \& it ended up knotted in his bladder ${ }^{(1)}$. The surgeon could not get it through a scope $\&$ the man had to have his bladder open up.

Van ophoven and dekernion reviewed 800 cases of penile foreign body insertion from 1755 to 1999[2]. The inserted objects fall into the following categories: Animals or parts of animals (coyote's rib, dog's penis, beech, snails, animal bones etc), plants \& vegetables (slippery elm, grass, cucumber, pistachio shells, etc.) Sharp \& lacerating objects (pencils, pins, needles etc), wire like objects (cable, catheter, rubber tube etc) and fluids and powders (nasal mucus, glue, cocaine, etc)[2]. Jaiswal described a 28 years old man with a penicillin bottle containing tincture of iodine, in the preputial sac[3]. The patient had inserted the bottle to tickle his glass penis during masturbation. The bottle was so firmly impacted the general anaesthesia was required to removed it.

The most common motive associated with foreign bodies of the genitiurinary tract is to geat sexual pleasure[4]. Penile foreign objects occurred with such frequency that every urologist \& practitioner may aspect to treat them.

But this was a case of introduction of foreign body into the urethra of a 26 years old male named Alamin by group of people as punishment of a girl \& that foreign body was wooden thorn (Bet Kata). This is not reported in the literature.

Insertion of the objects into penis is rarely fatal. Howevr, Byard et al, described a 40 years old man who inserted a pencil into his penis, where upon could not retrived. He developed a septic condition, did not sick medical help \& subsequently died[5].

Correspondence: Md. Nazrul Islam, Asst. Prof. Urology Dept., SBMCH, Barisal.
The management of urethral foreign body may require the use of various surgical techniques. A review of the literature revealed multiple methods for their extraction. We report a case of urethral foreign body, a wooden thorn (Bet Kata) not travarsing the prostatic urethrae \& lodging in the bulber rethra \& penil urethra, the tip of the foreign body were outside the urethra (about $2 \mathrm{~cm}$ out side from the tip) \& $15 \mathrm{~cm}$ inside the urethra, as it was thorned \& it was hook like and concavity inward, so it was indrawing inside slowly as it was about $6 \mathrm{~cm}$ outside the urethra after 3 hours it was only $2 \mathrm{~cm} \&$ it could not come out through the tip of the penis because if we tried then there was every chance of lacerated injury of the urethra on each side of the foreign body as the thorns all around the foreign body. The foreign body was removed using a small perineal incision and urethrotomy, avoiding the need for general anaesthesia.

To our knowledge, the use of percutaneous and endescopic techniques for urethral foreign body management has previously reported only one case[2], but removal of horny wooden beads (Bet Kata) not previously been reported.

\section{Case Report}

A 26 years old male presented to the MSU-1 (Urology Ward) in SBMCH with a history of introduction of a foreign body (Bet Kata) by few people as a punishment to tear a girl in a village, he presented with the history of perineal pain \& penile pain with hematuria with distension of urinary bladder for 24 hours. The patient was unable to pass urine. Physical examination was significant for a visible tip of foreign body at the tip (about $2 \mathrm{~cm}$ outside) of penis $\&$ for a palpable foreign body in the midline perinium \& also at the under surface of penis.

On digital rectal examination, the foreign body was palpable along the ant. rectal wall.

Using regional anaesthesia (spinal block), a small incision was made along the perineal raphe down to the foreign body $\&$ open the bulber urethra. This incision 


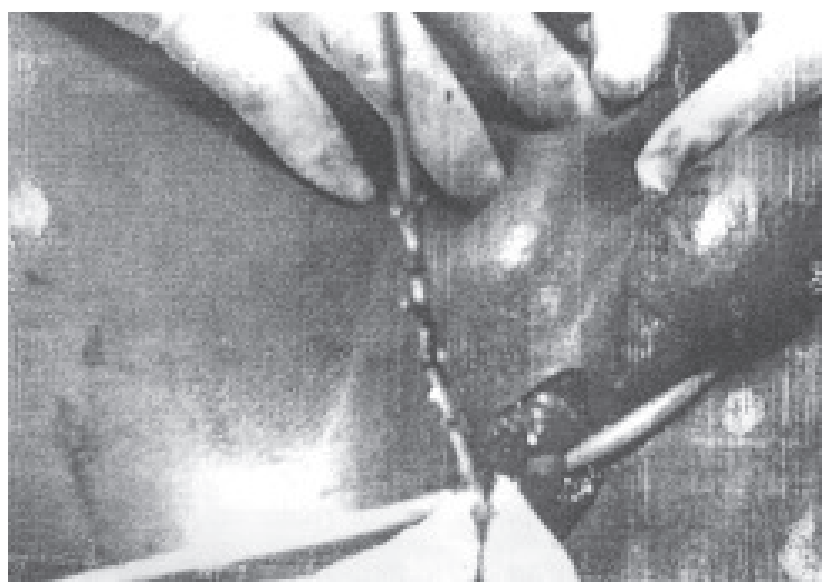

Fig.-1

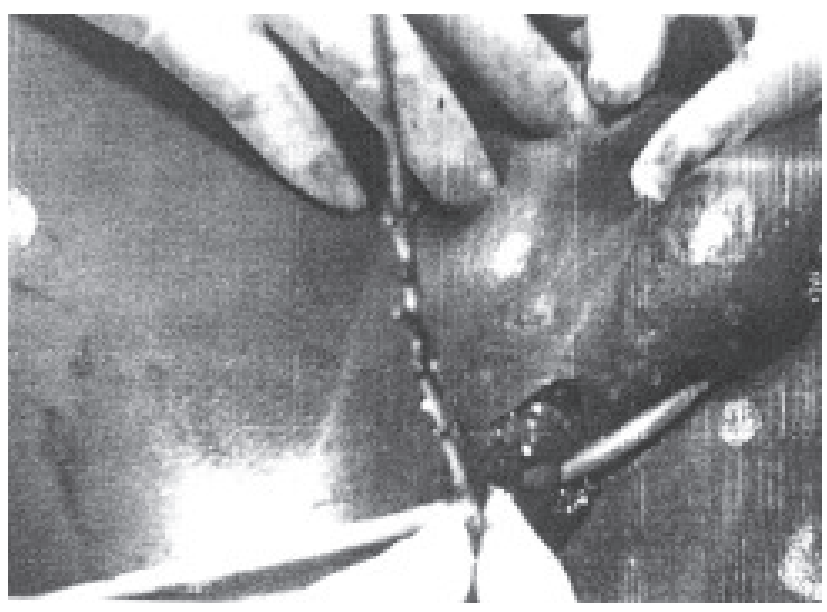

Fig.-2

facilitated the removal of the inner pole of Bet Kata, however, the outer pole also comes out with gentle traction through that incision \& the foreign body was identified as wooden thorn (Bet Kata). A 20 frence council tip foley's catheter was place into the urethra \& the perineal incision was closed in two layers with absorbable sutures.

The catheter was left indwelling for 3 weeks. A retrograde urethrogram (RUG) obtained after catheter removal revealed no evidence of extravasation or stricture. One year after the foreign body removal the patient still reports no viding difficulties.

\section{Conclusion:}

Several cases of urethral foreign bodies have been described in literature ${ }^{[2,6-7]}$. The reasons for urethral insertion are multifold ranging from dementia ${ }^{[6]}$ to intoxication ${ }^{[2]}$ to sexual experimentation \& / or play ${ }^{[7]}$, regardless of the motive for plceement of this foreign body \& its extrication can be challenging \& may require the creative use of urologists surgical armament in its removal. In this reported case a minimally invasive technique was employed to removal the urethral foreign body (Bet Kata) avoiding to use general anaesthesia. A small perinial incision was successfully used for this potentially challenging clinical dilemma. In conclusion, the technique of rethral foreign body removal should be as varied as the foreign bodies themselves \& should be dictated by the needs by individual case.

To our knowledge, the removal of Bet Kata as a urethral foreign body which was introduced by few people as a punishment of tissing girls has not be previously reported.

\section{References :}

1. SE Gold stone, the Ins and Outs gay Sex : a medical hard book for men Del publishing New York, NY. 1999 (the author is homosexual physician).

2. A Van Ophoven, J.B Dekernion, J Urol 164 (2) : 274-8 (7 Aug. 2000).

3. A.K. Jaiswal, Genitourin Med 68, 334 (Oct 1992)

4. G. W. Grument, J clin psychiatry 46, 537 (Dec. 1985).

5. R. W. Byard, D.A. Eitzen, R. James, Amj. Forensic Med Pathol 21, 65 (Mar. 2000).

6. Philips $\mathrm{J}$ : Fogarty Catheter extraction of unusual urethral foreign bodies, Jurol, 157 (4) : $1374-5$, 1996.

7. Ghaly AFF, Munishankar AR, Sultana SR, Nimmo $M$ : Case report; foreign body in male penile urethra, Genitourin Med, 72 (i) : 67 - 8, 1996. 